Article

\title{
Physical Characteristics of Coupled Plasma and Its Influence on Weld Formation in Hybrid Laser-Double-Arc Welding
}

\author{
Xiaoyan $\mathrm{Gu}^{1}{ }^{1}$, Yuchen Liu ${ }^{1}$, Wenhang $\mathrm{Li}^{1, *}$, Yujun Han ${ }^{2}$ and Kai Zheng ${ }^{3}$ \\ 1 Jiangsu Key Laboratory of Advanced Welding Technology, Jiangsu University of Science and Technology, \\ Zhenjiang 212003, China; liligu1983@163.com (X.G.); liuyuchen123@163.com (Y.L.) \\ 2 School of Materials Science and Engineering, Nanjing Institute of Technology, Nanjing 211167, China; \\ yujun.han@mail.wvu.edu \\ 3 Research and Development Center, CRRC Qingdao Sifang Rolling Stock Research Institute Co., Ltd, \\ Qingdao 266031, China; zheng_kai@tju.edu.cn \\ * Correspondence: lwh_jkl@just.edu.cn; Tel.: +86-159-9680-9316
}

Received: 11 November 2019; Accepted: 10 December 2019; Published: 14 December 2019

\begin{abstract}
Hybrid laser-double-arc welding (HLDAW) is an efficient welding method with multi-heat sources comprised of two arcs and a laser beam, which is an intricate process with much randomness and uncertainty due to the mutual effect between multi-plasmas. Compared with double-arc welding (DAW), HLDAW can generally obtain a more stable welding process and deeper weld penetration, which is directly affected by the synergistic effect of multiple heat sources; however, the mechanism has not been systematically studied. In this study, the multi-information analysis method is adopted to study the distribution of electron temperatures, electron densities and electrical conductivity of double-arc welding (DAW) and HLDAW by utilizing synchronous radiation spectrum, high-speed photography and electrical signal sensing technology. The results indicated that the high concentration of charged particles provided a conductive channel for the two arcs to achieve a more stable welding process in HLDAW. The synergy between the laser and the arc changed the flow mode of the weld pool, which facilitated the molten metal flowing toward the bottom of the molten pool. Obtaining the same melting depth, the line energy input of HLDAW was 13\% lower than that of DAW; the heat affected zone is narrower and the grain size is smaller. The weld penetration depth was improved in HLDAW, which was 1.8 times that of DAW and 1.5 times that of pure laser welding under the laser power of $1.5 \mathrm{~kW}$. The weld penetration of HLDAW increased with laser power.
\end{abstract}

Keywords: hybrid laser-double-arc welding; coupled plasma; electron temperature; electron density; arc shape

\section{Introduction}

Hybrid laser-double-arc welding (HLDAW) is a novel welding method based on double-arc welding and laser welding, and compared with hybrid laser-single-arc welding, this welding method can achieve higher welding speed, lower line energy and the gap allowance is up to $2 \mathrm{~mm}$ [1-3]. In addition, the welding process is more stable than double arc welding [4]. Moreover, this kind of welding equipment is free from the limitation of welding direction, and the arc space can be adjusted according to application, which can better realize automatic welding $[5,6]$. It has a great application prospect in welding low carbon steel, high strength steel and stainless steel, especially for the workpiece with a thickness of more than $20 \mathrm{~mm}$. 
However, compared to the hybrid laser single arc welding and arc welding, it is an intricate process with many randomness and uncertainties due to the mutual effect between triple heat sources $[7,8]$, which restricted its application.

At present, the research on HLDAW is less, and mainly focuses on the process exploration. $\mathrm{Hu}$ [9] analyzed the influence of the distance between two arcs on plasma interaction and droplet transfer through a high speed camera system and an electrical signal acquisition system. Wei et al. [4,10,11] qualitatively discussed the coupling mechanism of laser beam and arcs through an observation of electrical signals and high-speed camera signals in HLDAW. Gu et al. [12] calculated the largest Lyapunov exponent (LLE) of characteristic currents during the welding process under different arc distance by the phase space reconstruction technique to evaluate the stability of HLDAW. Gu et al. [13] discovered a special phenomenon alternative burning behavior of arcs in HLDAW and explored the change laws of alternative burning and its mechanism. The research results indicated that a certain synergy effect between laser and arcs brings benefits, and in some cases it is difficult to achieve better welding results [1,14-17]. A comprehensive and profound understanding of the synergy effect between laser and arcs will provides higher utilization of HLDAW in industry. Quantitative analysis of the synergy effect and its influences on the welding process are of great significance for optimizing welding quality.

In this paper, we examined electron temperatures, electron densities and electrical conductivity for coupled plasma of HLDAW using optical emission spectroscopy to better understand the physical characteristics of coupled plasma. Its influence on weld forming and penetration depth was further analyzed, meanwhile synchronous high-speed photography and electrical signal were adopted to observe arc shape to reveal the physical principle of the synergy effect in order to find the fundamental mechanism of HLDAW.

\section{Materials and Methods}

In this study, Q235B mild steel plate (Taiyuan Iron \& Steel (Group) CO., LTD, Taiyuan, China) with the dimensions of $310 \mathrm{~mm} \times 150 \mathrm{~mm} \times 12 \mathrm{~mm}$ was used as a base metal, while H08Mn2SiA copper (Sichuan Atlantic welding materials CO., LTD, Zigong, China)-coated wire with a diameter of $1.2 \mathrm{~mm}$ was used as filler material. The composition of the Q235B mild steel and the welding wire are shown in Table 1. Surfacing was adopted in this experiment. Argon was used as shielding gas with flow rate of $20 \mathrm{~L} \cdot \mathrm{min}^{-1}$.

Table 1. Chemical components of Q235 steel and H08Mn2SiA welding wire (wt \%).

\begin{tabular}{ccccccccc}
\hline $\mathbf{C}$ & $\mathbf{M n}$ & $\mathbf{S i}$ & $\mathbf{P}$ & $\mathbf{S}$ & $\mathbf{C r}$ & $\mathbf{N i}$ & $\mathbf{C u}$ & $\mathbf{F e}$ \\
\hline $0.14-0.22$ & $0.30-0.65$ & $\leq 0.3$ & $\leq 0.05$ & $\leq 0.045$ & - & - & - & $99.5-99.7$ \\
$\leq 0.11$ & $1.80-2.10$ & $0.65-0.95$ & $\leq 0.025$ & $\leq 0.015$ & $\leq 0.20$ & $\leq 0.30$ & $\leq 0.50$ & $95.8-96.4$ \\
\hline
\end{tabular}

The schematic illustration of the HLDAW system is shown in Figure 1. The welding machine employed in the experiment was composed of a ND: YAG laser (JK2003SM, GSI Group Laser Div. Rugby, England) with a maximum rated power of 2000 W. A Lincon INVERTEC V350-PRO (Lincoln welding machine (Shanghai) CO., LTD, Shanghai, China) power source and supporting wire feeder were used along with the laser device to achieve a hybrid welding process. A continuous wave ND: YAG laser beam of wavelength $1064 \mathrm{~nm}$ was concentrated on the surface of the workpiece with a spot radius of $80 \mu \mathrm{m}$ and the focal length of $300 \mathrm{~mm}$. The arc welding guns exist in same plane of weld bead. The angle between the central axes of these welding guns and our workpiece were kept at $60^{\circ}$. The laser beam was located in the same plane with the two welding guns, and the angle between them was $30^{\circ}$. The defocusing amount kept at $0 \mathrm{~mm}$, the distance between laser beam and welding tip was $3.5 \mathrm{~mm}$, the welding speed was kept $5 \mathrm{~mm} / \mathrm{s}$ and the wire feed rate was $2.5 \mathrm{~m} / \mathrm{min}$. There are 22 specimens prepared by pure laser, DAW and HLDAW, the specific welding parameters for every specimen are shown in Table 2. 


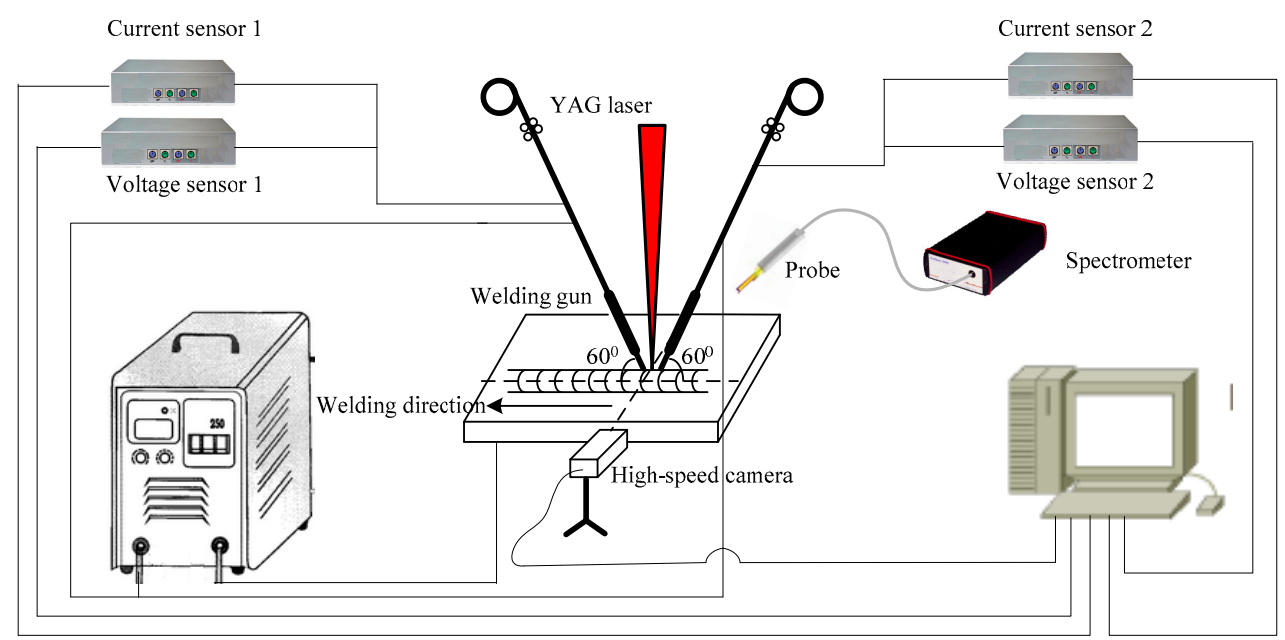

Figure 1. Schematic of the hybrid laser-double-arc welding (HLDAW) system.

The welding monitoring system adopted synchronous multi-information fusion technology, which comprised an electrical signal sensor device, (PCI-1742 DAQ Card, Acitetch- Newcite Information Technology Co.,Ltd, Shanghai, China) with the frequency of $10 \mathrm{kHz}$, a high-speed photography device (RockeTech technology Corp., Ltd, Changsha, China, CPL $250 \mathrm{~K} \mathrm{CMOS)} \mathrm{with} \mathrm{the} \mathrm{sampling} \mathrm{frequency} \mathrm{of}$ 1000 frames/s) for recording droplet transfer and welding plasma morphology and an optical detection device for detecting the light emission of hybrid plasma. A fiber optic spectrometer (AvaSpec-2048, Avantes Technology Co.,Ltd, Beijing, China) with wavelength range of 200-1100 nm and sampling precision of $0.09 \mathrm{~nm}$ was used as the detection device to detect the light emission of hybrid plasma. Specific welding parameters are shown in Table 1.

Table 2. Welding parameters.

\begin{tabular}{|c|c|c|c|c|}
\hline $\begin{array}{l}\text { Specimen } \\
\text { Number }\end{array}$ & $\begin{array}{c}\text { Laser Power } \\
\text { (W) }\end{array}$ & $\begin{array}{c}\text { Average Current } \\
\text { (A) }\end{array}$ & $\begin{array}{c}\text { Average Voltage } \\
\text { (V) }\end{array}$ & $\begin{array}{l}\text { Welding Speed } \\
(\mathrm{mm} / \mathrm{s})\end{array}$ \\
\hline $1 \#$ & \multirow{2}{*}{1500} & $\longrightarrow$ & - & 5 \\
\hline $2 \#$ & & $\longrightarrow$ & - & 5 \\
\hline $3 \#$ & \multirow{3}{*}{0} & 111.5 & 30.6 & 5 \\
\hline $4 \#$ & & 110.8 & 30.2 & 5 \\
\hline $5 \#$ & & 111.4 & 30.5 & 5 \\
\hline $6 \#$ & \multirow{3}{*}{600} & 113.2 & 31.1 & 5 \\
\hline 7\# & & 112.7 & 29.9 & 5 \\
\hline $8 \#$ & & 113.3 & 29.4 & 5 \\
\hline $9 \#$ & \multirow{3}{*}{800} & 114.6 & 28.9 & 5 \\
\hline $10 \#$ & & 114.1 & 28.7 & 5 \\
\hline $11 \#$ & & 113.8 & 28.6 & 5 \\
\hline 12\# & \multirow{3}{*}{1300} & 114.4 & 28.2 & 5 \\
\hline 13\# & & 115.2 & 28.2 & 5 \\
\hline $14 \#$ & & 114.3 & 27.7 & 5 \\
\hline $15 \#$ & \multirow{3}{*}{1500} & 116.3 & 27.4 & 5 \\
\hline $16 \#$ & & 116.8 & 27.3 & 5 \\
\hline $17 \#$ & & 116.2 & 26.9 & 5 \\
\hline $18 \#$ & \multirow{2}{*}{1500} & 116.6 & 27.7 & 8 \\
\hline 19\# & & 116.3 & 27.4 & 8 \\
\hline $20 \#$ & \multirow{3}{*}{1800} & 118.4 & 26.7 & 5 \\
\hline $21 \#$ & & 117.5 & 26.1 & 5 \\
\hline 22\# & & 117.1 & 25.9 & 5 \\
\hline
\end{tabular}


In this experiment, a long, thin, hollow tube with a diameter of $1.0 \mathrm{~mm}$ was mounted towards the probe to collect the light emitted from the hybrid plasma. In this way, the spatial location of the collection point can be obtained accurately. In addition, the thin tube limits the amount of light passing through, resulting in a significant reduction in radiation intensity, which is effective for resolving the problems of radiation saturation and spectrograph protection. The measurement point distribution was shown in Figure 2, y1 is $0.5 \mathrm{~mm}$ above the plate surface, y2 is $2.0 \mathrm{~mm}$ above the plate surface and the top layer y3 is $6 \mathrm{~mm}$ above the plate surface. In this experiment, it was easily to obtain the spectral radiation intensity at the peak pulse, because the three kinds of signals including electrical signals, high-speed camera signals and spectral signals, were synchronized. To ensure accuracy, each point is measured three times, and the average value is taken as the radiation intensity at this point.

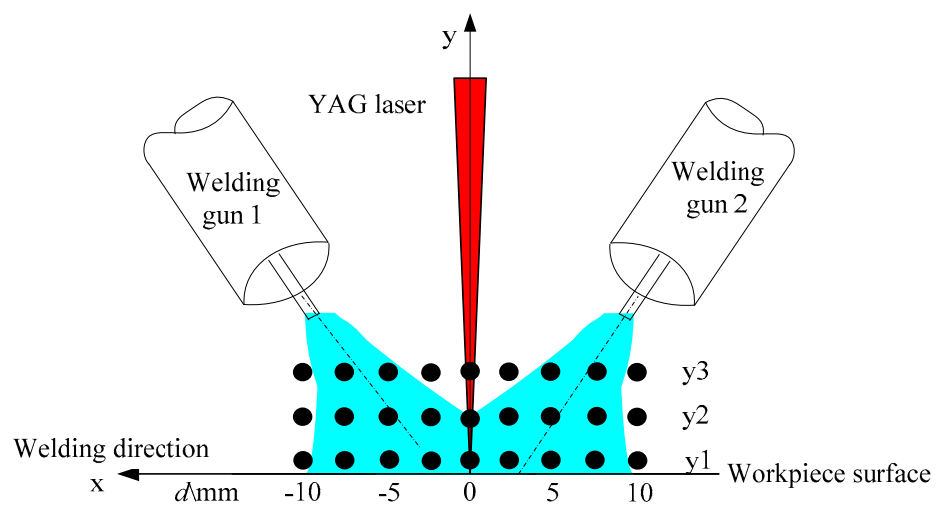

Figure 2. Measurement points distribution.

\section{Results and Discussion}

It is assumed that hybrid plasma of HLDAW should be optically thin and in local thermal equilibrium (LTE). By this assumption, the distribution of energy in the plasma region follows Maxwell's equation [18]. The LTE assumption can be satisfied due to sufficiently high electron density [19]:

$$
N_{e} \geq 1.6 \times 10^{12} T_{e}^{1 / 2}(\Delta E)^{3}\left(\mathrm{~cm}^{-3}\right)
$$

where $N_{e}$ is the electron density, $T_{e}$ is the electron temperature, and $\Delta E$ is the energy gap.

The maximum electron temperature of HLDAW plasma is below $20,000 \mathrm{~K}$, the maximum $\Delta E$ of the selected FeI feature lines is $3.0646 \mathrm{eV}$. According to Equation (1), the minimum electron density of the welding plasma satisfying the local thermodynamic equilibrium condition is $6.45 \times 10^{15} \mathrm{~cm}^{-3}$.

The intensity of a spectral line emitted characteristic line satisfies the expression as follows when atoms transit from higher energy $m$ to lower energy $n$ [20]:

$$
\ln \left(\frac{I_{m n}}{v_{m n} g_{m} A_{m n}}\right)=-\frac{m}{\kappa T_{e}}+D
$$

In which, $D$ is constant, $A_{m n}$ is the transition probability, $g_{m}$ is the statistic-weight factor, $m$ is the energy in the higher level, $I_{m n}$ is the radiation intensity, $v_{m n}$ is the radiation frequency and $\kappa$ is the Boltzmann constant. In Equation (2), $m$ is set as $X$-axis and $\ln \left(I_{m n} / v_{m n} g_{m} A_{m n}\right)$ as $Y$-axis.

The specific method is selecting several line spectra of the same element and obtaining the corresponding point plotted on the XOY plane coordinates through every selected line spectrum by Equation (2). After fitting points linearly, the electron temperature $T_{e}$ can be obtained from its slope.

Figure 3 is the calibration of the feature spectrum line between $605-630 \mathrm{~nm}$. In this paper, four FeI lines $(629.77927 \mathrm{~nm}, 617.33352 \mathrm{~nm}, 600.30119 \mathrm{~nm}$ and $606.5482 \mathrm{~nm})$ were chosen as characteristic lines to calculate the electron temperature of hybrid plasma on different layers. The parameters of the feature spectrum lines are shown in Table 3. 


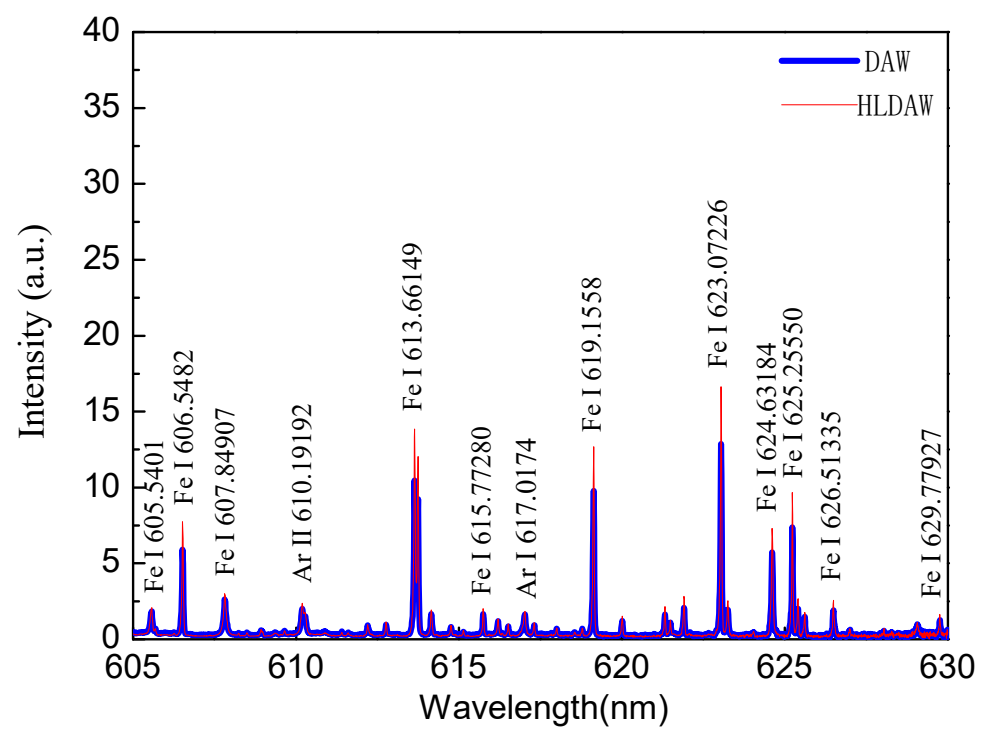

Figure 3. Calibration of feature spectrum line between $605-630 \mathrm{~nm}$.

Table 3. Parameters of the feature spectrum line [21].

\begin{tabular}{ccccc}
\hline$\lambda / \mathbf{n m}$ & $A_{\boldsymbol{k} i} / \mathbf{s}$ & $\boldsymbol{E}_{\boldsymbol{k}} / \mathbf{c m}^{-\mathbf{1}}$ & $\boldsymbol{E}_{\boldsymbol{i}} / \mathbf{c m}^{\mathbf{- 1}}$ & $g_{\boldsymbol{k}}$ \\
\hline 629.77927 & $6.12 \times 10^{4}$ & $33,801.572$ & $17,927.382$ & 5 \\
617.33352 & $2.31 \times 10^{5}$ & $34,121.603$ & $17,927.382$ & 1 \\
600.30119 & $1.79 \times 10^{5}$ & $47,960.940$ & $31,307.245$ & 9 \\
606.5482 & $1.07 \times 10^{6}$ & $37,521.161$ & $21,038.987$ & 5 \\
\hline
\end{tabular}

The electron density of arc plasma can be acquired from Equation (3) [21]:

$$
N_{e}=\frac{\Delta \lambda_{1 / 2}^{S}}{2 \omega} \Delta 10^{16}
$$

In which, $\Delta \lambda_{1 / 2}^{S}$ is full width at half maximum, $\omega$ is coefficient of electron collision-broadening, which can be obtained from [21,22].

Spectral lines with appropriate intensity and good separability were selected and fitted linearly by Lorentz to obtain $\Delta \lambda_{1 / 2}^{S}$. In this research, ArI 706.7218 was selected as a characteristic spectral line to calculate $N_{e}$. The fitting results were shown in Figure 4.

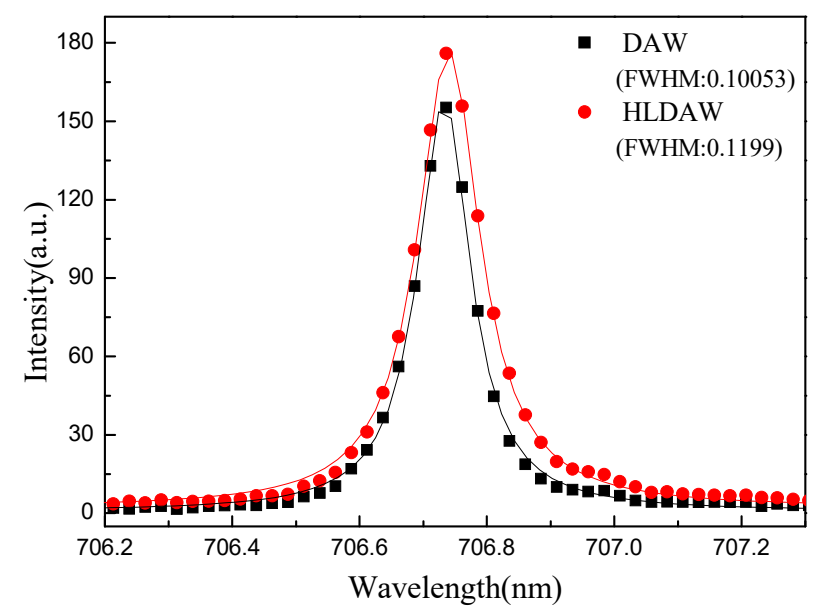

Figure 4. Lorentzian fitting of the Stark broadened profile for ArI $706.7218 \mathrm{~nm}$. 
The electron temperature of the hybrid plasma calculated from Equation (2) ranges from 12,000 to $17,000 \mathrm{~K}$. According to [21], the value of $\omega$ is $0.0066 \mathrm{~nm}$.

Figure 5 shows the continuous spectral radiation of the midpoint of two arcs on layer y1 in different laser powers. Figure $5 \mathrm{a}$ is the radiation intensity of DAW, while $\mathrm{b}$ and $\mathrm{c}$ are the radiation intensity after $0.5 \mathrm{~kW}$ and $1.5 \mathrm{~kW}$ laser addition, respectively.

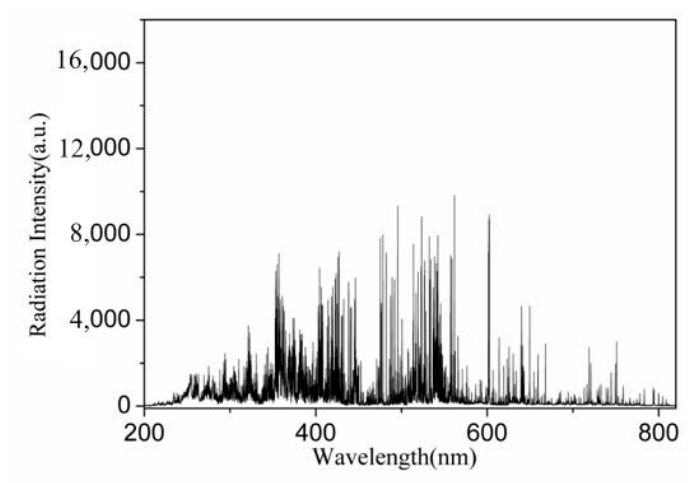

(a)

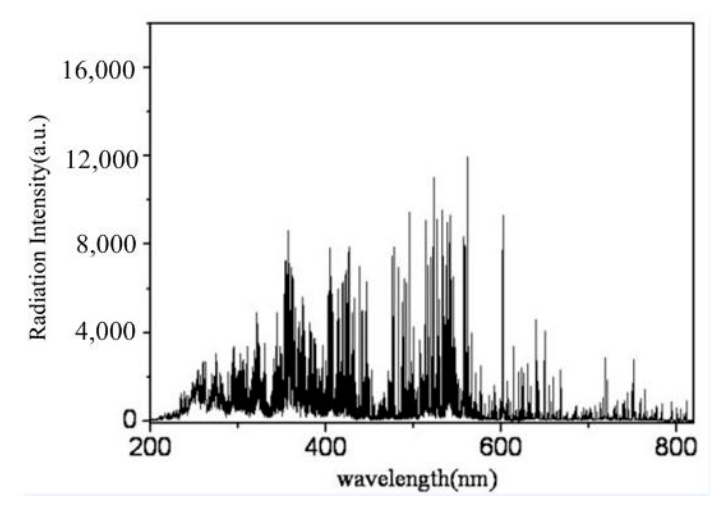

(b)

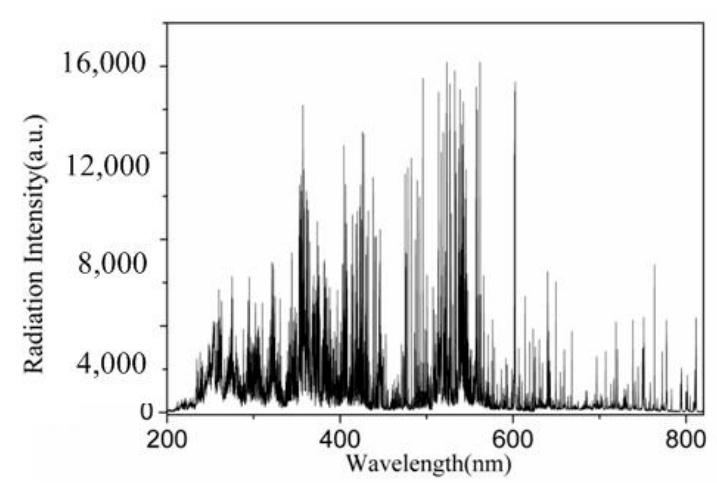

(c)

Figure 5. Radiation comparison of laser point in different laser powers. (a) without laser (b) with 500 W laser (c) with $1.5 \mathrm{~kW}$ laser.

It can be obtained from Figure 5 that the radiation spectrum of hybrid plasma was basically the same as that before the laser addition, where there were a large number of lines distributing on a continuous spectrum. The line spectrum was composed of FeI, FeII ranging from 200 350 nm, FeI 
ranging from 350 690 nm and ArI ranging from $690 \sim 820 \mathrm{~nm}$. However, the radiation intensity of HLDAW was stronger than that of DAW, especially in the UV-visible region that is mainly dominated by iron particles. In addition, the radiation intensity increased with laser power. It means that the introduction of laser could not bring new radiation lines, but increase the degree of particle ionization, and this enhanced effect improved with the increase of laser power.

Figure 6 is the electron temperature distribution of different layers on peak pulse current with and without laser addition. It can be seen that the variation trends of electron temperature were almost the same with and without laser addition. For DAW, the temperature of the region near the midpoint of the two arcs $(-5 \sim 5 \mathrm{~mm})$ was higher than that of the region far away from the midpoint of the two arcs on the lower surface. The overall temperature distribution in middle layer (y2) was greater than the lower layer, and the zone with highest temperature and great gradient was formed on the midpoint of the two arcs, which was about $16,800 \mathrm{~K}$. With further increase of the distance from the plate (y3), the temperature on the midpoint of the two arcs significantly decreased to about $15,000 \mathrm{~K}$, the temperature peak on this layer was in the arc center, which was about $16,200 \mathrm{~K}$, and the temperature distribution of other region was almost the same with y2.

For HLDAW, temperature distribution was similar with that of DAW. The temperature on the lower layer was about $1000 \mathrm{~K}$ higher than that of DAW. The highest temperature was also on the mid-tier layer (y2), which was about 17,200 K and $400 \mathrm{~K}$ higher than DAW. However, the overall temperature on $\mathrm{y} 3$ declined dramatically, even below that of $\mathrm{y} 1$.

The above calculation of electron temperature shows that the energy of HLDAW heat system increased, especially in the region near the weld pool.

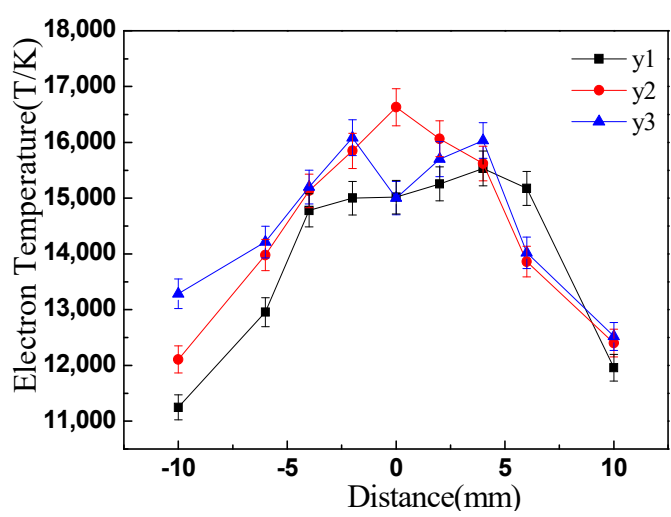

(a)

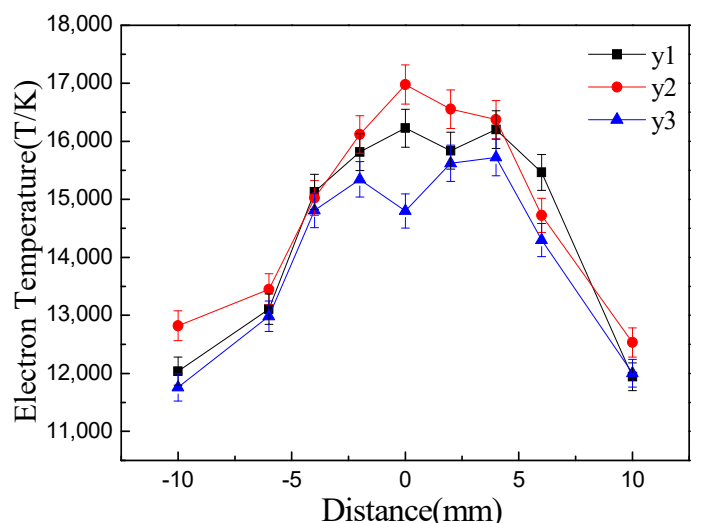

(b)

Figure 6. Distribution of electron temperature. (a) double-arc welding (DAW) (b) hybrid laser-double-arc welding (HLDAW) $(\mathrm{P}=1.5 \mathrm{~kW})$.

Figure 7 shows the electron density distribution on a region close to molten pool (layer y1). It can be seen that the electron density of DAW and HLDAW presented a similar distribution trend, the peak regions were both in the center of arc column, while the electron density is lower in the regions that far away from the arc column. The electron density distribution of HLDAW is similar with DAW, but it is larger than that of DAW as a whole. The electron density mutated in the laser point, which is 1.25 times that of DAW. 


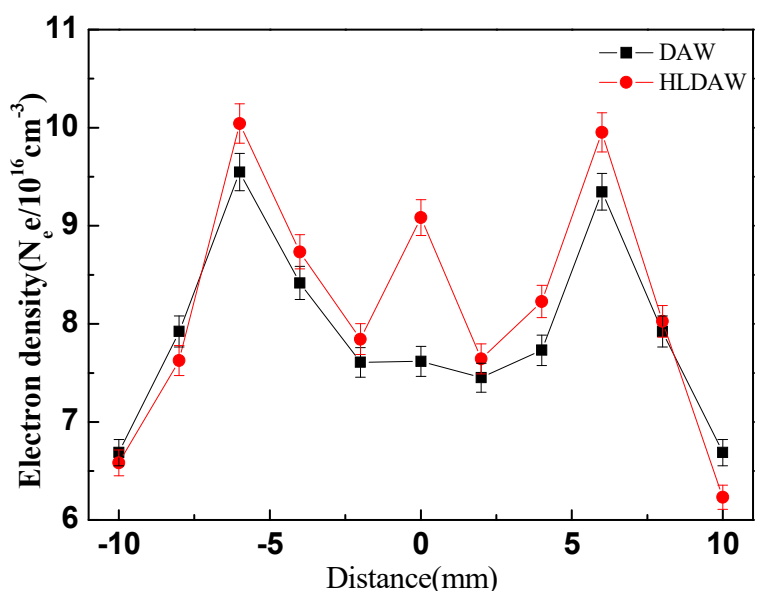

Figure 7. Distribution of electron density (layer 1).

Figure 8 provides direct photographic evidence for the results above. In order to be more intuitive, the left arc in the two welding processes was selected for a comparison. Figure 8 is the arc morphology of DAW (a) and HLDAW (b) of peak pulse current. It can be observed that the angle between vertical direction and the central line of the arc was $33.7^{\circ}$, the arc-column diameter was $2.44 \mathrm{~mm}$, and half of the distance between the two arc-roots was about $8.0 \mathrm{~mm}$ in DAW.

However, after addition of the $1.5 \mathrm{~kW}$ laser, the angle between vertical direction and the central line of the arc increased to $45^{\circ}$, the arc-column diameter reduced to $1.72 \mathrm{~mm}$ and the half spacing between the two arc-roots shortened to about $4.0 \mathrm{~mm}$.

It demonstrated that the laser beam was imposing contraction and attraction on arcs, which made the cross section of the arc column smaller and the arc-root closer to the laser spot impinging on the molten pool surface.
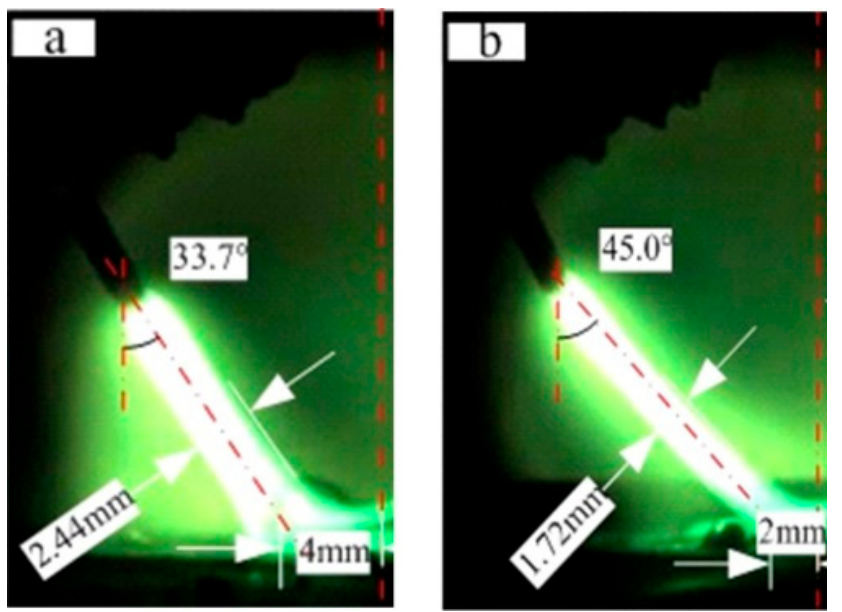

Figure 8. Arc shape of DAW and HLDAW. (a) Without laser (b) with $1.5 \mathrm{~kW}$ laser.

In the welding process, metal of droplet and molten pool evaporated and ionized by absorbing the arc energy to result in the increases of the concentration of iron ions in the arc atmosphere. Compared with $\mathrm{Fe}$, the ionization potential of $\mathrm{Ar}$ in the shielding gas is relatively small. The concentration of $\mathrm{Ar}$ ions in the arc atmosphere is lower. So, compared with ArI ranging from 650 1100 nm, the radiation intensity of FeI ranging from $200 \sim 350 \mathrm{~nm}$ and $350 \sim 690 \mathrm{~nm}$ is stronger. It indicated that the energy input of this welding system increased after laser addition to lead to the ionization of metal and the increase of metal vapor concentration, and this enhanced effect increases with the increase of laser power. 
During the welding process, both of the shielding gas and gasified workpiece material further ionized into electrons and charged particles by absorbing heats to result in the increases of concentration of charged ions in the arc atmosphere.

The ionic potential of iron atoms is $762.5 \mathrm{~kJ} \mathrm{~mol}^{-1}$, much lower than that of the argon, which is $1520.6 \mathrm{~kJ} \mathrm{~mol}^{-1}$. Therefore, the number of ions was significantly higher than that of argon ions, and that which was shown in the spectrogram was that the quantity of iron emission lines was larger than that of argon, and the radiation intensity was also stronger. In the HLDAW process, at the position where the laser spot impinges upon the workpiece surface, the material was obviously vaporized because of the absorption of laser energy, and then the steam transported into the arc plasma [23-25]. The ionic potential of the atmosphere around the arc is reduced effectively. In addition, some of the laser beam energy can be absorbed by the arc plasma, which will help to further ionize the arc plasma [26].

Compared with DAW, the radiation intensity of these charged particles was much stronger in HLDAW, especially in the regions that were occupied by iron ions.

It can be inferred from Figures 5 and 6 that the electron temperature and electron density near the center line of two arcs (laser beam in HLDAW) on the lower layer were prominently increased after introduction of the laser into this welding system.

The conductivity of the coupled plasma can be represented as [27]:

$$
\begin{gathered}
\sigma=\frac{n_{e} e^{2}}{m_{e} v_{e i}} \\
v_{e i}=\frac{8}{\pi}\left(\frac{e^{2}}{4 \pi \varepsilon_{0}}\right)^{2}\left(\frac{n}{m_{e}^{\frac{1}{2}} T_{e}^{\frac{3}{2}} K_{b}^{\frac{3}{2}}}\right) \ln \Lambda
\end{gathered}
$$

where $n_{e}$ is the electron density, $v_{e i}$ is the collisions frequency between electrons and neutral particle, $e$ is the electron charge, $m_{e}$ is the electron mass, $\mathrm{K}_{b}$ is Boltzmann's constant, $T_{e}$ is electron temperature, $\ln \Lambda$ is the coulomb logarithm. It can be inferred from Equations (4) and (5) that the conductivity of the coupled plasma increased with the electron temperature and electron density. Thus, the high concentration of charged particles provided a conductive channel for the two arcs. According to the principle of minimum voltage, the arc will automatically select the combustion region with the least resistance. In this way, the arc roots were confined to the laser spot impinging on the workpiece surface, achieving a stable welding process.

Figure $9 \mathrm{a}, \mathrm{b}$ show the dynamic process of the arc within $15 \mathrm{~ms}$ at a welding speed of $8 \mathrm{~mm} / \mathrm{s}$ during DAW and HLDAW, respectively. It demonstrated that the drifting of arc-root and severe bending of arc-column occurred as the electrode moving forward because of the mutual interference between the two arcs in DAW at a high welding speed. However, more stable cathode spots and smoother arc were obtained due to the conducting path near the laser point on the workpiece surface formed by the ionized particles, which makes the welding process stable after adding the $1.5 \mathrm{~kW}$ laser in HLDAW.

(a)
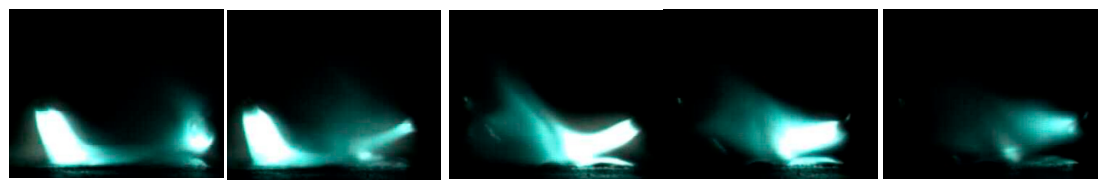

(b)
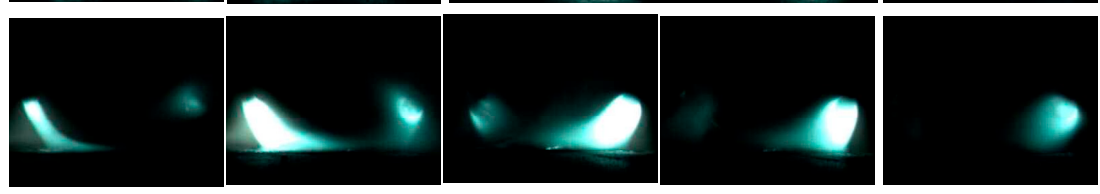

Figure 9. Dynamic process of arc. (a) DAW (b) HLDAW $(\mathrm{P}=1.5 \mathrm{~kW})$.

The material at the point of deposition rises in temperature to the boiling point, which converts liquid to superheated vapor. Once vapor is formed, it expands and is released upward from the surface, 
and produces a reaction force that presses the melt downward and sideways. The depressed surface of the weld pool permits additional photos from the laser beam and electrons/ions from the arc to impinge upon fresh material, which is then heated in the same way. In DAW, the driving force on the molten surface produced by two arcs pushing the melted metal flowing from the center to the edge of the weld pool is shown in Figure 10a.

In the process of HLDAW, the liquid metal flow in the molten pool was different from that of DAW because of the addition of the laser, as shown in Figure 10b. The depression of the weld pool surface becomes larger because of the laser beam and transforms to a keyhole, the entire central core of which consists of vapor surrounded on all sides by an envelope of liquid metal [28]. The reaction force produced by vapor ejected upward from the keyhole facilitates the molten metal flowing toward the bottom of the molten pool. Meanwhile, the laser beam can pass through the keyhole and heat the bottom surface of penetration directly.

(a)

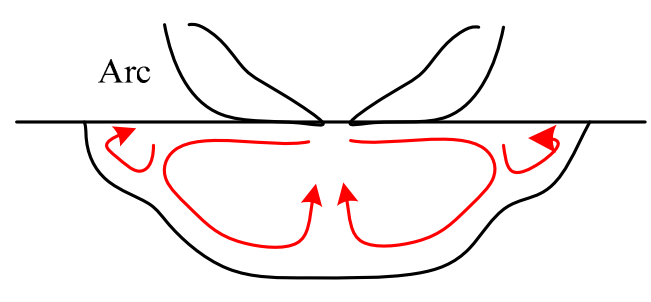

(b)

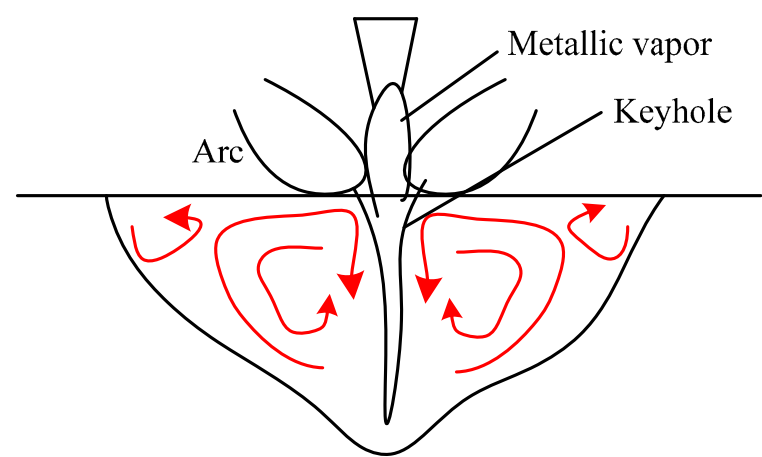

Figure 10. Comparison of liquid flow in molten pool. (a) DAW (b) HLDAW.

The drawing and compressing imposed by the laser beam on two arcs made the arc column shrink and increasing of electron density, which enhanced the Lorentz force in the molten pool. It increased the current density of the laser point location on the molten pool surface, promoting the liquid metal from the periphery of the weld pool to the center and then to the bottom.

In HLDAW, the surface deformation is the synthetical result caused by multiple forces including the arc pressure, the evaporation counterforce and the surface tension. The force on the free surface of the molten pool is expressed as follows:

$$
P=P_{A}+P_{R}-P_{S}
$$

where $P_{A}$ is the arc pressure, $P_{R}$ is the evaporation counterforce and $P_{S}$ is the surface tension.

The compression of the arc column reduces the contact area between arc and liquid pool, which increases the arc blowing pressure on the pool and further helping the liquid metal to flow to the bottom.

In conclusion, the addition of the laser changed the flow of liquid metal in this HLDAW process. The flowing from the periphery to the center of the pool enhanced the heat transfer to the bottom of the pool, which was helpful for the high temperature and superheated liquid metal to move downward the bottom of the pool and increase the weld depth. The increases of welding penetration depth in HLDAW are also dependent largely upon the impact force of rapid-floating charged particles applied on the workpiece surface. Both of the number of charged particles and traveling speed are improved with the increase of laser intensity, thus increasing this impact force on the workpiece.

Table 4 shows the morphologies of the appearance and cross sections of the welding seam obtained by pure laser welding (2\#), DAW(3\#) and HLDAW(16\#). Compared with pure laser welding and DAW, the weld penetration was deeper and the surface was more regular and smoother in HLDAW. It was found that the upper part of the weld penetration presented the characteristics of DAW, while the 
lower part presented the characteristics of pure laser welding. The weld depth is larger than that of pure laser welding and DAW.

Table 4. Schematic of weld surface and section in DAW and HLDAW $(P=1.5 \mathrm{~kW})$.

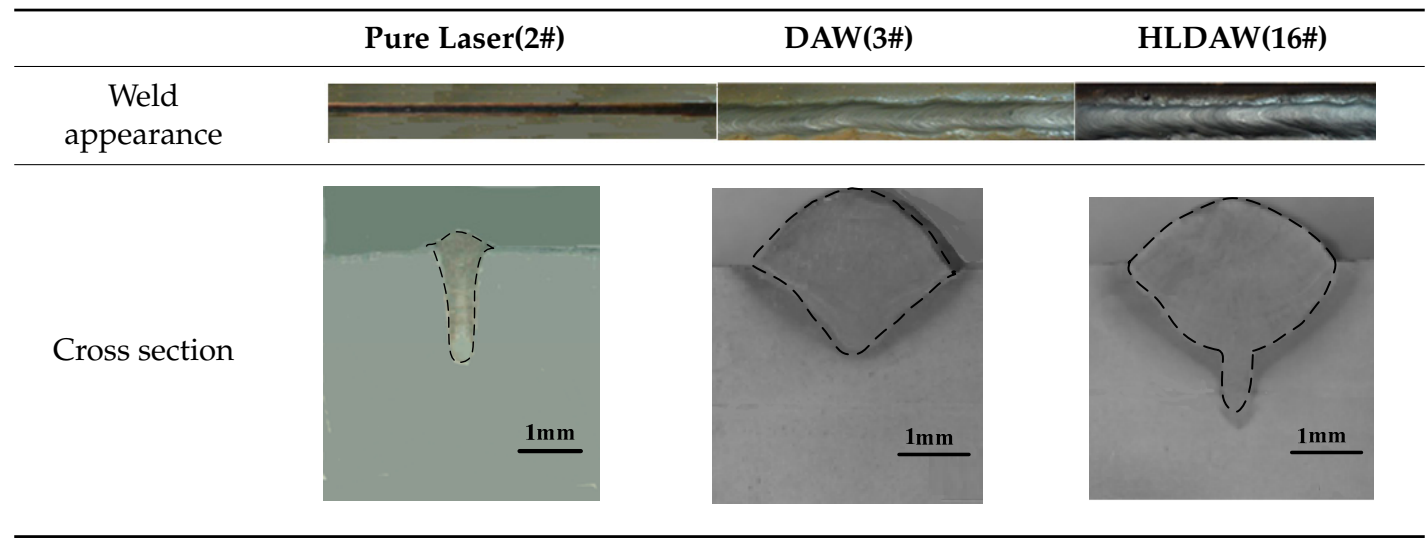

Figure 11 is the weld penetration comparison of pure laser welding, DAW and HLDAW with various laser powers. The weld penetration depth was improved in HLDAW, which was 1.8 times that of DAW and 1.5 times that of pure laser welding under the laser power of $1.5 \mathrm{~kW}$. The weld penetration of HLDAW increased with laser power. Under the condition of this experiment, when the laser power was small, the energy density irradiated by the YAG laser onto the surface of the molten pool was relatively low, the synergy between laser and arc was weak and the temperature of molten metal in the middle of the molten pool was not significantly increased. Therefore, the melting depth of the HLDAW weld displayed the characteristics of the DAW weld. As the laser power increased beyond a certain threshold (600 W in this experiment), a mutually strengthening effect was achieved.

The higher the laser power, the higher the laser energy density at the laser point on the surface of the molten pool, which increases the temperature in the middle of the molten pool, resulting in the greater increase in the weld depth of HLDAW.

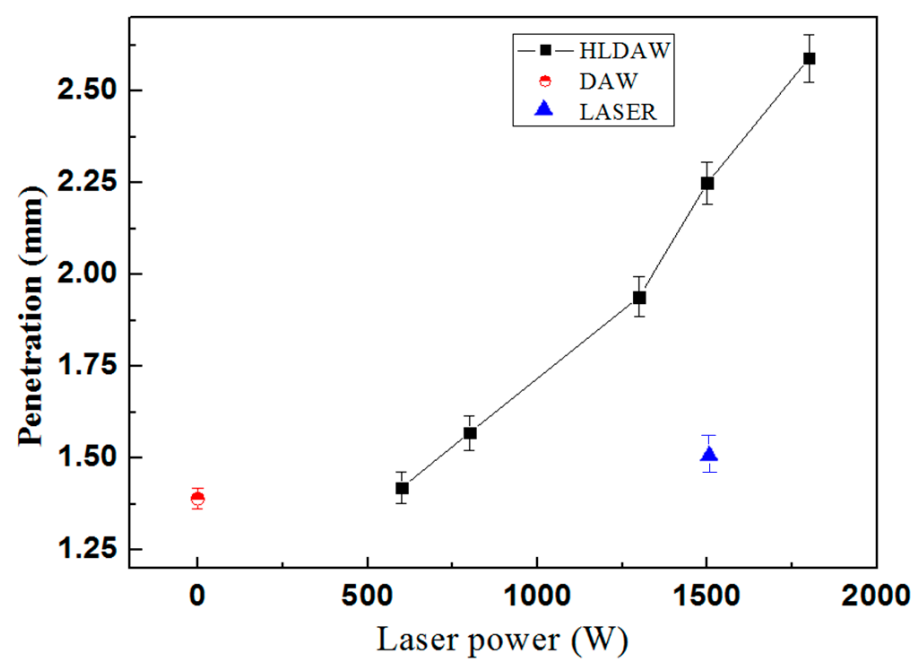

Figure 11. Penetration of DAW and HLDAW.

In addition to these differences in weld pool geometry, the microstructure of the weld with the same depth obtained by two welding methods ( $3 \#$ and 18\#) is compared in Figure 12. Obtaining the same weld penetration, the line energy input of DAW was $682 \mathrm{~J} / \mathrm{mm}$, while the line energy input of HLDAW was only $591 \mathrm{~J} / \mathrm{mm}$, which is reduced by $13 \%$. It was found that the microstructure of the weld zone or heat-affected zone was basically the same, except for a little difference in grain size. The 
microstructure of this weld was composed of columnar proeutectoid ferrite with intergranular acicular ferrite and pearlite. Compared with DAW, the microstructure and quantity of the proeutectoid ferrite precipitated along grain boundaries were tiny, and the superheated grains in the heat-affected zone were relatively small in the HLDAW weld. This indicated that the weld microstructure obtained by HLDAW is finer than DAW.
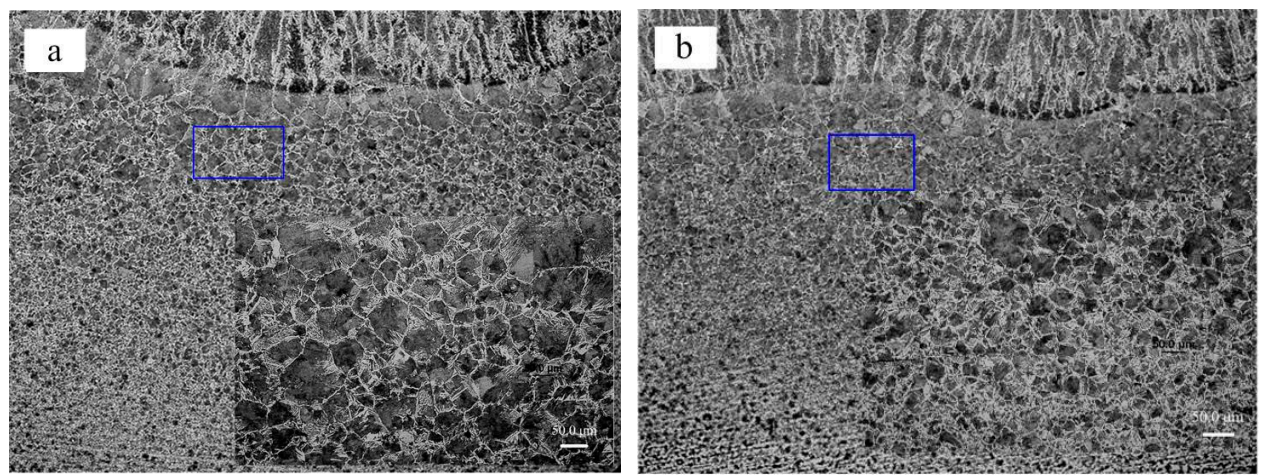

Figure 12. Microstructure of welded Q235B. (a) DAW(3\#) $v=5.0 \mathrm{~mm} / \mathrm{s},(\mathbf{b}) \operatorname{HLDAW}(18 \#) v=8.0 \mathrm{~mm} / \mathrm{s}$.

\section{Conclusions}

Based on the present study, the physical characteristics of coupled plasma and its influence on weld formation in HLDAW have been investigated. The following conclusions were drawn:

(1) The laser beam has significant influence on the shape, characteristic and energy distribution of the arc, and at the same time, the energy and transmission characteristics of this arc will be changed to some extent under the effect of the laser beam, which will modify the energy coupling, temperature distribution, fluid flow behavior and further influence the welding process.

(2) The experimental results showed that the electron density in the heat source center of HLDAW was 1.25 times that of DAW. The high concentration of charged particles provided a conductive channel for the two arcs, so as to restrain the drifting of arc roots during high-speed welding and obtain a more stable welding process.

(3) The reaction force produced by vapor ejected upward from the keyhole facilitates the molten metal flowing toward the bottom of the molten pool. The flowing from the periphery to the center of the pool enhanced the heat transfer to the bottom of the pool, which was helpful for the high temperature and superheated liquid metal to move downward the bottom of the pool and increase the weld depth. The preheating of the arc also intensifies the "digging" effect of the laser. The low-density arc dilutes the electron density of the laser plasma and reduces the absorption and reflection of laser energy by laser plasma to improve the penetrating effect of the laser beam. The above factors lead to the different flow modes of HLDAW from DAW, and obtain the greater weld depth.

(4) The experiment results showed that obtaining the same melting depth $(1.39 \mathrm{~mm})$, the line energy input of HLDAW was 13\% lower than that of DAW, the heat affected zone is narrower and the grain size is smaller. The weld penetration depth was improved in HLDAW, which was 1.8 times that of DAW and 1.5 times that of pure laser welding under the laser power of $1.5 \mathrm{~kW}$. The weld penetration of HLDAW increased with laser power.

Author Contributions: Conceptualization, X.G.; methodology, X.G. and W.L.; data curation, K.Z.; investigation, Y.L. and Y.H.; resources, X.G.; writing-original draft preparation, X.G.; writing-review and editing, X.G.; supervision, W.L.; funding acquisition, X.G.

Funding: This research was funded by National Natural Science Foundation of China (NSFC), grant number 51705218; Natural Science Foundation of China (NSFC), grant number 51775255; Natural Science Foundation of Jiangsu Province, grant number BK20161358; Natural Science Foundation of the Jiangsu Higher Education Institutions of China, grant number 16KJA460006.

Conflicts of Interest: The authors declare no conflict of interest. 


\section{References}

1. Dilthey, U.; Keller, H. Prospects in laser GMA hybrid welding of steel. In Proceedings of the First International WLT-Conference on Lasers in Manufacturing, Munich, Germany, June 2001; AT-Fachverl: Fellbach, Germany, 2001; pp. 453-465.

2. Bappa, A. Hybrid laser arc welding: State-of-art review. Opt. Laser. Technol. 2018, 99, 60-71.

3. Olsen, F.O. Hybrid Laser-Arc Welding; Woodhead Publishing Limited: Great Abington, UK, 2009.

4. Wei, H.L.; Li, H.; Yang, L.J.; Gao, Y.; Ding, X.P. Arc characteristics and metal transfer process of hybrid laser double GMA welding. Int. J. Adv. Manuf. Technol. 2015, 77, 1019-1028. [CrossRef]

5. Zhang, C.; Gao, M.; Zeng, X.Y. Influences of synergy effect between laser and arc on laser-arc hybrid welding of aluminum alloys. Opt. Laser. Technol. 2019, 120, 105766. [CrossRef]

6. Chen, J.; Han, Z.K.; Wang, L.; Wu, C.S. Influence of arc interactions on heat and mass transfer during a two-arc hybrid welding. Int. J. Heat. Mass. Tran. 2019, 11, 119058. [CrossRef]

7. Kiran, D.V.; Cho, D.W.; Song, W.H.; Na, S.J. Arc behavior in two wire tandem submerged arc welding. J. Mater. Process. Tech. 2014, 214, 1546-1556. [CrossRef]

8. Li, R.F.; Li, Z.G.; Zhu, Y.Y.; Rong, L. A comparative study of laser beam welding and laser-MIG hybrid welding of Ti-Al-Zr-Fe titanium alloy. Mat. Sci. Eng. 2011, 528, 1138-1142. [CrossRef]

9. Hu, L.H.; Huang, J.; Liu, C.T.; Liu, X.L. Effects of coupling between the laser plasma and two arcs on metal transfer in $\mathrm{CO}_{2}$ laser double-wire MIG hybrid welding. Opt. Laser. Technol. 2018, 105, 152-161. [CrossRef]

10. Gu, X.Y.; Li, H.; Yang, L.J.; Gao, Y. Coupling mechanism of laser and arcs of laser-twin-arc hybrid welding and its effect on welding process. Opt. Laser. Technol. 2013, 48, 246-253. [CrossRef]

11. Gu, X.Y.; Li, H.; Jiang, X.B.; Sheng, H.C. Effect of laser on droplet transfer and welding process stability in hybrid laser + double arc welding. Int. J. Adv. Manuf. Tech. 2017, 89, 2981-2991. [CrossRef]

12. Gu, X.Y.; Li, H.; Luo, J.S. Lyapunov exponent analysis for the evaluation of hybrid laser double-arc welding process stability. Appl. Optics. 2018, 57, 9053-9061. [CrossRef]

13. Gu, X.Y.; Yong, D.; Luo, J.S. Study on the alternative burning behavior of arcs in hybrid laser-double-arc welding. Int. J. Adv. Manuf. Tech. 2019, 102, 2581-2590. [CrossRef]

14. Shinn, B.W.; Farson, D.F.; Denney, P.E. Laser stabilization of arc cathode spots in titanium welding. Sci. Technol. Weld. Join. 2005, 10, 475-481. [CrossRef]

15. Chen, M.H.; Li, X.Y.; Liu, L.M. Effect of electric field on interaction between laser and arc plasma in laser-arc hybrid welding. IEEE T. Plasma. Sci. 2012, 40, 2045-2050. [CrossRef]

16. Zhang, Z.Z.; Xu, G.X.; Wu, C.S. Thermal field model for laser pulse GMAW-P hybrid welding of tcs stainless steel based on the predicted keyhole shape. Acta. Metall. Sin. 2011, 47, 1450-1458.

17. Xu, G.X.; Li, P.F.; Cao, Q.N.; Hu, Q.X.; Du, B.S. Modelling of fluid flow phenomenon in laser+GMAW hybrid welding of aluminum alloy considering three phase coupling and arc plasma shear stress. Opt. Laser. Technol. 2018, 100, 244-255. [CrossRef]

18. Kiran, D.V.; Cho, D.W.; Song, W.H.; Na, S.J. Arc interaction and molten pool behavior in the three wire submerged arc welding process. Int. J. Heat. Mass. Tran. 2015, 87, 327-340. [CrossRef]

19. Moradi, M.; Ghoreishi, M.; Frostevarg, J.; Kaplan, A.F.H. An investigation on stability of laser hybrid arc welding. Opt. Laser. Eng. 2013, 51, 481-487. [CrossRef]

20. Greim, H.R. Plasma Spectroscopy; McGraw-Hill: Cambridge, UK, 1964.

21. NIST Atomic Spectra Database [DB/OL]. Available online: http://physics.nist.gov/PhysRefData/ASD/lines_ form.html (accessed on 25 October 2019).

22. Chen, F.F. Introduction to Plasma Physics; Plemun Press: New York, NY, USA, 1974.

23. Wang, J.; Wang, C.M.; Meng, X.X.; Hu, X.Y.; Yu, Y.C.; Yu, S.F. Interaction between laser-induced plasma/vapor and arc plasma during fiber laser-MIG hybrid welding. J. Mech. Sci. Technol. 2011, 25, 1529-1533. [CrossRef]

24. Song, G.; Wang, H.Y.; Li, T.T.; Liu, L.M. Joining mechanism of Mg alloy/steel butt joints with Cu-Zn interlayer by hybrid laser-TIG welding source. J. Iron. Steel. Res. Int. 2018, 25, 221-227. [CrossRef]

25. Degout, D.; Catherinot, A. Spectroscopic analysis of the plasma created by a double-flux tungsten inert-gas (TIG) arc plasma torch. J. Phys. D. Appl. Phys. 1986, 19, 811-823. [CrossRef]

26. Xu, G.X.; Wu, C.S.; Ma, X.Z.; Wang, X.Y. Numerical Analysis of Welding Residual Stress and Distortion in Laser plus GMAW Hybrid Welding of Aluminum Alloy T-Joint. Acta. Metall. Sin. 2013, 26, 352-360. [CrossRef] 
27. Xu, G.X.; Li, P.F.; Li, L.; Hu, Q.X.; Zhu, J.; Gu, X.Y.; Du, B.S. Influence of Arc Power on Keyhole-Induced Porosity in Laser + GMAW Hybrid Welding of Aluminum Alloy: Numerical and Experimental Studies. Materials 2019, 12, 1328. [CrossRef] [PubMed]

28. Zhang, C.; Li, G.; Gao, M.; Zeng, X.Y. Microstructure and mechanical properties of narrow gap laser-arc hybrid welded $40 \mathrm{~mm}$ thick mild steel. Materials 2018, 10, 106. [CrossRef] [PubMed]

(C) 2019 by the authors. Licensee MDPI, Basel, Switzerland. This article is an open access article distributed under the terms and conditions of the Creative Commons Attribution (CC BY) license (http://creativecommons.org/licenses/by/4.0/). 